\title{
Endeavoring with Body Area Network and Suffering from Electric Shooting
}

\author{
Tao $\mathrm{Wu}^{*}$ \\ Shenzhen Research Institute of Sun Yat sen University, China \\ *Corresponding author: Tao Wu, Shenzhen Research Institute of Sun Yat-sen University, China
}

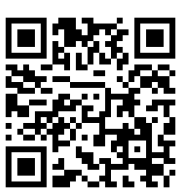

\section{ARTICLE INFO}

Received: 唪 December 17, 2019

Published: 幽January 06, 2020

Citation: Tao Wu. Endeavoring with Body Area Network and Suffering from Electric Shooting. Biomed J Sci \& Tech Res 24(1)2020. BJSTR. MS.ID.004007.

Keywords: Body Area Network; Internet of Things; Electronic Shooting; Robot; Microcosmic World

\section{ABSTRACT}

Body Area Network (BAN) has been widely used for sports, health and recognition, while the well-known minimally invasive operation uses its information in medical sciences. Nevertheless, the electronic shooting at human beings in society is overwhelmingly increasing these days. Such shooting activities greatly threaten people's health and securities. In fact, person is usually located and identified by the Internet of Things (IoT) and then shot by the help of body area network. In other words, the IoT is like the absolute coordinate in environments, and the BAN looks like the relative coordinate in physics. The electric discharges from lots of corners and holes within the IoT and nets act as the shooting at a human being. Especially, it can hit the mustaches into the respiratory passages and noses, causing many illnesses to the person. The other important issue with modern medical science refers to Robots and human intelligence. It has been found that many animals and pets are just Robots with smartness. The risk of adopting pets lies on that it may acts under the control of other persons.

Abbreviation: BAN: Body Area Network; IoT: Internet of Things; NMR: Nuclear Magnetic Resonance; CT: Computed Tomography

\section{Introduction}

Just like the integrated circuits that bring out power and efficiency from the microcosmic world [1], the body area network reflects the details and fluctuations within a person's body. The tissues can be observed and examined by X-rays, Nuclear Magnetic Resonance (NMR) and Computed Tomography (CT), with which modern medical science can be set up on science and technology with accuracy and tests. It can be used to find out whether there are any changes with the body. Also, the movements of muscles can be recorded to guide his acts in sports and plays. More importantly, body area network may be used to identify a person like face recognition and fingerprint recognition. From another point of view, the body area network is the big data of a human being's health. There is a great amount of information about the person covered in his or her body area network [2]. Nevertheless, it is strange that the body area network not only brings big data about persons, but also gets out of much trouble around them. The electronic shooting, so far, the most significant problem with personal security, utilizes both the Internet of Things and the body area network to attack people. The discharging electricity comes from holes and pins in the walls, pipes, floors, and poles, and goes into the corresponding pairs connected in the background. The electric shooting with more than two directions may cause tension in the things, therefore causing brokenness. Many shooting ways in the air may support pieces of paper and dust floating.

\section{Body Area Network and Minimally Invasive Operation}

Body area network is the biological network based on human bodies consisting of organs with vessels, bones, muscles, and nerves. In addition, skins and hairs can also be included for detections and observations. Body area network can be used in sports, health and recognition. as is shown in Figure 1. The so-called minimally invasive operation has been widely used in surgery since 1990s [3]. It can be thought of as accurate tensile electric shooting, as is shown in Figure 2. Typically, there are a great amount of discharging and charging pins and holes on the ceiling, the walls, and the grounds. The electric shooting hits a position on the person and behaves as a small operation with knife or needle. 


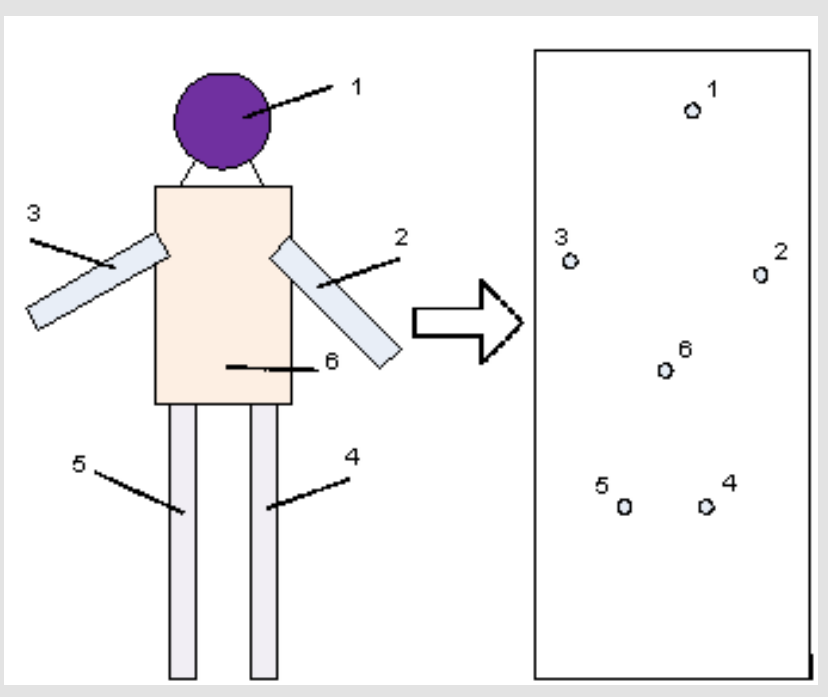

Figure 1: Illustration of body area network.

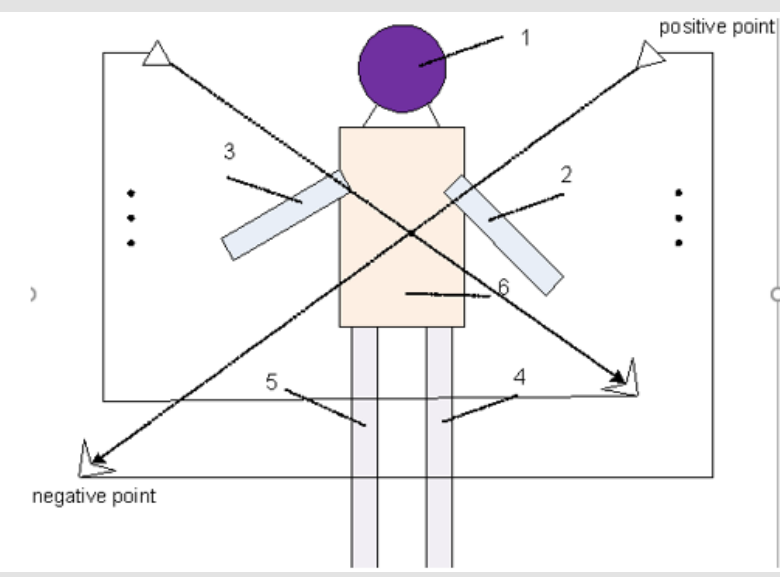

Figure 2: Electronic shooting.

\section{Electric Shooting, Mustache and Lungs}

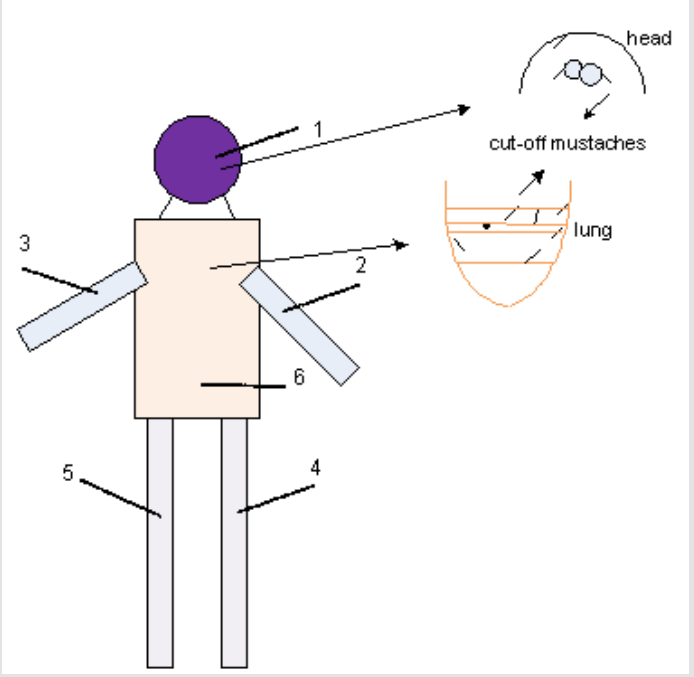

Figure 3: Cut-off mustaches into the head and the lung.
The electric shooting may be suddenly started by anonymous persons and beats people from about all points of view. In modern buildings, it is even hard to avoid the electric shooting in one's habit. As far as we know, one paramount challenge occurs with man's cutting off mustaches, which may be shotted into his noses and arrive at his respiratory passages and lungs. It seems that the vibrissa in medicine are just mustaches flowed into the noses. As a matter of fact, both the mustaches and the small cut-off hairs may be shotted into one's lungs and heads, as are shown in Figure 3.

Also, the irritability with noses may also be caused by mustaches flied into the noses and the electric shooting. The headache and catching a cold are assumed to be caused by the electric shooting and mustaches too. It is supposed that the recovery of a human being with such illnesses needs to repel such mustaches out of one's body, for which the electric shooting is still deemed as the appropriate choice.

\section{Internet of Things, Robots and Pets}

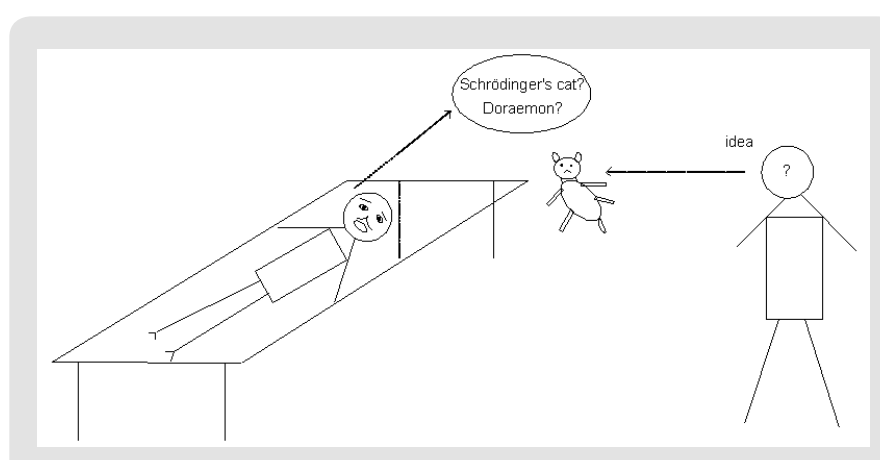

Figure 4: Schrödinger's Cat or Doraemon.

People live in a world of all things in a network. The stationary computers, televisions, and telephones are all connected to the Internet by the human beings. By contrast, Internet of things connect almost all intelligent objects and things around them even without human beings. While the Internet emphasizes on the person, the Internet of Things or IoT focuses on the connectivity and communication of things [4]. The IoT provides several services for the society: Firstly, it charges and discharges electricity to maintain a surveillance network. For example, it provides the location of carriages and persons passing through them. Secondly, it collects information about the environments and receive instructions to control Robots. Nowadays, there are many Robots in the streets and countryside. Many animals and pets are in fact Robots. A speculation is that the cloning in biology is manufacturing a similar Robot. A majority of unanimous cats and dogs may be Robots, which are charged and connected by wireless IoT. The danger with big animals lies not only on the electric power and shooting, but also on the personal ideas behind. As is shown in Figure 4, the Schrödinger's cat in quantum mechanics is used to describe the doubt of the cat's liveness. "As described by quantum mechanics, the cat is simultaneously alive and dead until it is observed [5]." 
In the famous Japanese cartoon Doraemon, the cat is able to call on much power and strength to finish some unexpected tasks. It seems that such ability is partly supported by the smart grids with electricity [6].

\section{Conclusion}

Electric shooting with IoT is an increasing problem around the world, which points at human beings by the big data of body area network. A case in point refers to the minimal invasive operation, which is presumed to be just accurate tensile electric shooting Next, the cut-off mustaches may be shotted into people's lungs and heads by electricity, incurring many kinds of respiratory diseases. It had better that such mustaches be recorded and shotted out of one's body for health. Finally, the IoT also provides information and

ISSN: 2574-1241

DOI: 10.26717/BJSTR.2020.24.004007

Tao Wu. Biomed J Sci \& Tech Res

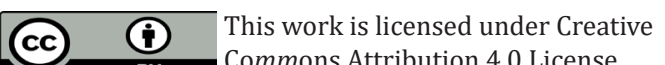

Submission Link: https://biomedres.us/submit-manuscript.php power to maintain Robots in the environments, which are supposed to include many alive animals.

\section{References}

1. JM Rabaey, A Chandrakasan, B Nikolic (1996) Digital Integrated Circuits: A Design Perspective. Upper Saddle River.

2. M Chen, S Gonzalez, A Vasilakos, H Cao, VCM Leung (2010) Body area networks: A survey. Mobile Networks and Applications 16(2): 171-193.

3. WR Chitwood, CL Wixon, J R Elbeery, N A Francalancia, R M Lust (1999) Minimally invasive cardiac operation: Adapting cardioprotective strategies. Annals of Thoracic Surgery 68(5): 1974-1977.

4. (2013) An introduction to the internet of things (IoT). Lopez Research.

5. (2018) Schrödinger's cat. https://fermi.gsfc.nasa.gov/science/ constellations/pages/schrodinger.html

6. T Vijayapriya, DP Kothari (2011) Smart grid: An overview. Smart Grid and Renewable Energy 2(4): 305-311.

$\begin{array}{ll}\text { BIOMEDICAL } & \text { Assets of Publishing with us } \\ \text { RESEARCHES } & \text { - Global archiving of articles } \\ & \text { - Immediate, unrestricted online access } \\ & \text { - Rigorous Peer Review Process } \\ \end{array}$

